\title{
BIOASSAY OF ACETYLCHOLINE WITH A THIN MUSCLE STRIP OF THE JAPANESE MEDICAL LEECH: A PRELIMINARY NOTE ON THE REAPPRAISAL OF THE AVAILABILITY OF THIS METHOD
}

\author{
Ken KADOTA and Mitsuhiro NAGATA* \\ Department of Pharmacology, Osaka University Medical School, Kita-ku, Osaka 530, \\ and ${ }^{*}$ Kansii Medical School, Moriguchi, Osaka 570, Japan
}

Accepted May 28, 1975

In European countries, the muscle response of the medical leech (Hirudo medicinalis) has been found effective in the bioassay of acetylcholine $(\mathrm{ACh})^{(-2), 5), 7 \sim 11}$; in Japan, however, despite the high sensitivity and specificity of leech dorsal muscle to this amine, this method has been considered to be practically disadvantageous owing to the poor nuscle response following induced contraction ${ }^{12}$. On the other hand, it was found that if a strip of the dorsal muscle as thin as $0.2-0.4 \mathrm{~mm}$ was prepared from the worm following Szerb's 'and Whittaker's procedures ${ }^{11}$ the specimen contracted with $\mathrm{ACh}$ relaxed well within 5 min following rinse. A thinly prepared muscle strip was highly sensitive to ACh. During the winter season, February and March, it contracted in response to $\mathrm{ACh}$ over a range of $10^{-8}-10^{-20} \mathrm{~g} / \mathrm{ml}$. We report herein our findings on a promising bioassay procedure for $\mathrm{ACh}$ using the Japanese medical leech hitherto regarded as a material of no practical use.

The medical leech, possibly identical with Hirudo nipponia Whitran seen in Japan, Korea, and Formosa ${ }^{6}$, was purchased from a local drug house dealing in Chinese medicines. A leech, usually $30-40 \mathrm{~mm}$ long, was pinned down on its back through the mouth- and tail-suckers in a suitably extended position, onto a cork board covered with filter paper, mouth towards the operators, and a cut was made with scissors along one lateral line from the mouth nearly to the tail. The ventral and dorsal walls were pinned down, inside up, at either side along the cut line, and the internal organs, such as the whitish intestine and diverticula, were bluntly removed with forceps (Fig. 1a). The dorsal muscle was cut longitudinally about $0.2 \mathrm{~mm}$ wide and $20 \mathrm{~mm}$ long with double razor blades (Fig. 1b). Two thin threads were attached, about $15 \mathrm{~mm}$ apart, at each end of the muscle strip, and the specimen was removed from the lecch. During all these procedures, the muscle was often soaked with drops of a diluted mammalian Locke solution described by Szerb ${ }^{9}$, 5 parts Locke : 4 parts water (DML). The removed muscle strip was suspended in a Whittaker"s microbath with a capacity of $0.2 \mathrm{~m}^{11}$, fixing one thread onto the bottom of the bath and attaching the other to a transducer whose minimal sensitivity to displacement force was $1 \mathrm{mg}$. The Iransducer was connected to a recorder (AS-3A, Shinko Tsushin Co., Osaka). The specimen was allowed to stand for $1 \mathrm{hr}$ during which time the preparation was washed and sensitized with an eserinized, diluted mammalian Locke (EDML), the DML containing 
SHORT COMMUNICATIONS

Japan. J. Pharmacol. 25, 603 (1975)

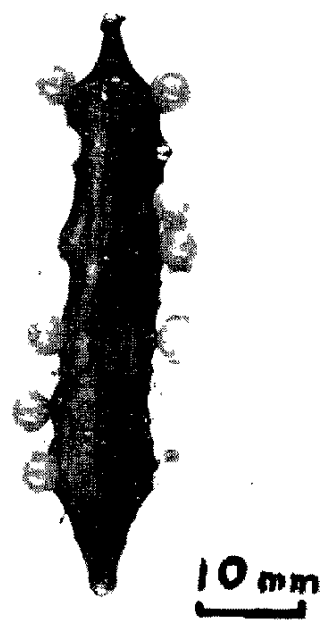

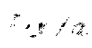

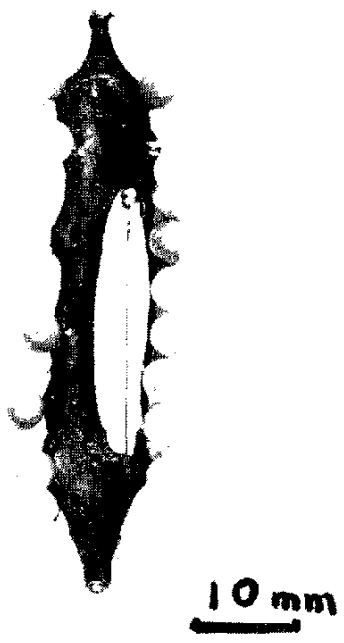

Fit.

FIG. 1. (a) The walls of a medical leech, inside up, after the removal of the internal organs. Left half; ventral wall. Right half: dorsal wall. (b) A dorsal muscle strip, about $0.2 \mathrm{~mm}$ wide and $20 \mathrm{~mm}$ long, cut along the dorsal median line.

eserine sulphate $(1 \mathrm{mg} / 100 \mathrm{ml})$. The fluid, EDML, came down continuously from a restervair to the bath, soaked the muscle strip, and then flowed out through an overflow to an aspirator ${ }^{11}$. Before adding AChe, the supply of EDML was stopped. The fluid, EDML, remaining in the bath was removed by suction with the tip of the aspirator, and a dose of AChe (AChe chloride), diluted in EDML and $0.2 \mathrm{ml}$ in volume, was put into the bath. The agonist was allowed to act for 0.5 or 1 min depending on the sensitivity of the muscle responge, after which time the thin muscle strip was rinsed by EDML. Usually, the muscle relaxed well within 5 min after the starting of the wash. When a low muscle response was observed, an increasing amount of AC was added in an exponential progression of 2 . The sensitivity of the muscle response to $\mathrm{ACh}$ varied from preparation to preparation: the muscle strip contracted in response to AC over a range of $10^{-8}-10^{-20} \mathrm{~g} / \mathrm{ml}$, this range being lower than that reported by previous workers using the Japanese medical leech ${ }^{3 \sim 4,}$, 12 13). Fig. 2 shows a typical muscle response: 0.5 min contractures with $A C h$ over a range of $1 / 8 \times-1 \times 10^{-1 \mathrm{~g}} \mathrm{~g} / \mathrm{ml}$ and relaxation processes within $5 \mathrm{~min}$ following rinse. The threshold of the muscle response is low and the relaxation is rapid. The dose-response curve is seen to be quite linear on a semilogarithmic graph paper (Fig. 2; Inset). The muscle response seemed fairly specific to $\mathrm{ACh}$ in comparison with the other agonists tested. The muscle which contracted with $\mathrm{ACh}$ at $10^{-10} \mathrm{~g} / \mathrm{ml}$ did not respond to the following substances $(\mathrm{g} / \mathrm{ml}$ doses in parentheses): choline chloride $\left(10^{-4}\right)$, noradrenaline hydrochloride $\left(10^{-}\right)$, dopamine hydrochloride $\left(10^{-2}\right)$, histamine hydrochloride $\left(10^{-i}\right)$, serotonin creatinine sulphate $\left(10^{-7}\right)$, tryptamine hydrochloride $\left(10^{-4}\right)$, sodium glutamate $\left(10^{-2}\right)$, glutamine $\left(10^{-2}\right), \gamma-$ aminabutyric acid $\left(10^{-2}\right)$, and glycine $\left(10^{-2}\right)$. 

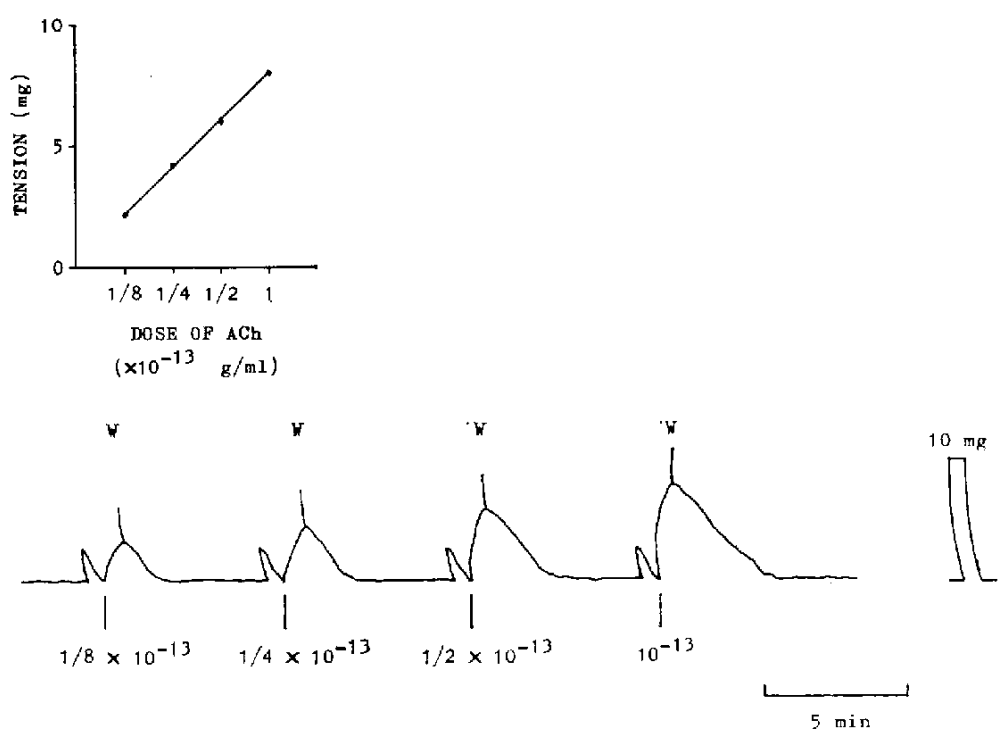

FiG. 2. A record of the muscle response to ACh over a range of $1 / 8-1 \times 10^{-13} \mathrm{~g} / \mathrm{ml}$. The amine was added with 5.5 -minute cycle; contraction for 0.5 min followed by washing for $5 \mathrm{~min}$ for relaxation. Water temperature: $18^{\circ} \mathrm{C}$. Inset: The dose-response curve of the specimen is shown in Fig. 2. Plottcd on a semilogarithmic paper.

Four factors in preparation were found critical for muscular relaxation and contraction threshold: 1) A preparation thicker than $0.5 \mathrm{~mm}$ would not relax well, as Whittaker had pointed out ${ }^{10 ;}$. Lsually a thick muscle took a long time to relax, i.e. 15-20 min or even more, as previous workers who had used the Japanese medical leech for Ach bioassay have reported ${ }^{4,12 ?}$. Moreover, the thick muscle strip was found to be in sensitive to ACh. 2) The second factor which affected threshold and relaxation was the temperature of the solution used in soaking the muscle (see ref. 12). The effects of temperature between $13-21^{\circ} \mathrm{C}$ were tested: below $15^{\circ} \mathrm{C}$ the muscle would neither respond to a high dose of the amine, e.g. $1 \times 10^{-6} \mathrm{~g} / \mathrm{ml}$ or more, nor relax well. In some cases, the muscle which had responded well to one dose of $\mathrm{ACh}$ would not give any contracture on a second try with the same dose. 3) The third point found critical was the time spent in isolating the muscle strip. The more rapid operation gave the better preparation, i.e. the one more satisfactory in both relaxation and contraction. To specd up muscle isolation neither the skin nor the brown fat covering the muscle strip were removed. 4) The fourth point is a selection of the portion to be cut out. Since the dorsal skin and the brown fat are too thin to remove from the muscle without damaging the preparation, an elaborate removal of skin and fat often results in the worst preparations. Care was paid to cut out the muscle strip along the dorsal median line, this portion having the least amount of brown fat.

Acknowledgements: Gratitude is due to Prof. V.P. Whittaker, Abt. Neurochem., Max-Planck Institute, Göttingen, for his kind demonstration to one of authors (K.K.) of the practices of his ACh bioassay method with the thin muscle strip from the leech. For 
facilities and assistance, the authors also wish to thank Dr. K. Takikawa of the Taiho Pharmaceutical Co. Ltd., Tokushima, Japan.

\section{REFERENCES}

1) FC̈hnfR, H.: Biochem. Z. 92, 347 (1918); 2) Fülintr, H.: Arch. exp. Path. Pharmakol. 82, 51 \& 81 (1918;; 3) Fukumoto, T.: J. Chiba Med. Soc. 17, 127 (1939); 4) Furuyama, Y., Ikeda, M., and Ohkubo, Y.: Japan. J. Veterinary Sci. 25, 33 (1963); 5) HebB, C. AND Morrus, D.: In: The Stricture and Function of Nervous Tissue, vol. III, Edited by G.H. Bourne, Academic Press, New York and London, 1970, p. 25; 6) Kergan, H.L., Toshioka, S., And Suzuki, H.: In: Blood sucking Asian leceches of famities Hirudae and Haemadipsidae, A contribution from the Departmint of Entomology, 406th Medical Laboratory, U.S. Army Medical Command, Japan, 1968, p. 23; 7) Minz, B.: Arch. exp. Path. Pharmakol. 168, 292 (1932); 8) QuasreL, J.H., Tentenzaum, M., AwD Whfati.fy, A.H.M.: Biochem. $J .30,1668(1936)$; 9) Szerb, J.C.: $J$. Physiol. 158, \& P (1961); 10) Whittaker, V.P., Micilaelson, I.A., and Kirkland, R.J.A.: Biochem.J. 9:, $293(1964)$; 11) WhitTAKER, V.P.: In: Preparation and use of subcellular fractions in neurochemistry, Laboratroy Notes, Edited by V.P. WintTAkfR, A. II. $5 ; 12$ ) YoNeZAwA, S.: Okayana Igakkai Zasshi 54,691 \& 861 (1942); (in Japanese); 13) YoshidA, T. AND Yoshimlra, M.: Folia pharmacol. japon. 51, 715 (1955) (in Japanese)

\section{ERRATUM}

K. KADOTA and M. NAGATA: Vol. 25, No. 5, p. 602 605 (1975). page 604, line 5:

correct: Moreover, the thick muscle strip was found to be poor in sensitivity to ACh. incorrect: Moreover, the thick muscle strip was found to be in sensitive to $\mathrm{ACh}$. 